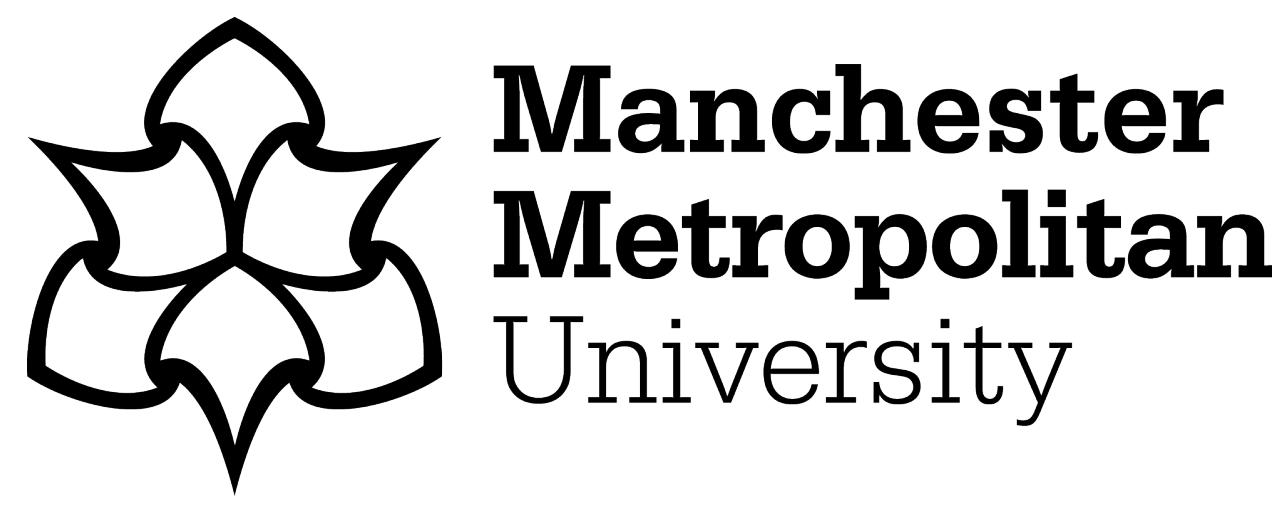

Calvey, David (2019) The everyday world of bouncers: a rehabilitated role for covert ethnography. Qualitative Research, 19 (3). pp. 247-262. ISSN 1468-7941

Downloaded from: https://e-space.mmu.ac.uk/621144/

Version: Published Version

Publisher: Sage

DOI: https://doi.org/10.1177/1468794118769782

Please cite the published version 


\section{The everyday world of bouncers: a rehabilitated role for covert ethnography}

\author{
David Calvey \\ Manchester Metropolitan University, UK
}

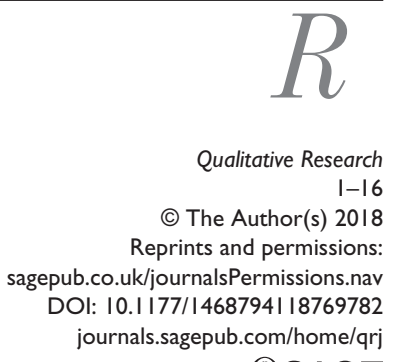

@SAGE

\begin{abstract}
The focus of this article is on the everyday world of bouncers in the night-time economy of Manchester, England. The structure of the article is to contextualise my covert passing in this demonized subculture followed by explorations of the everyday world of bouncers through the related concepts of door order and the bouncer self. A part of the article is an examination of the management of situated 'ethical moments' during the fieldwork and, more generally, critical reflections on emotionality, embodiment and risk-taking in ethnography. I also reflect on the retrospective and longitudinal nature of my fieldwork immersion, and both the data management challenges and possibilities this brings. Covert ethnography can be a creative part of the ethnographer's tool kit and can provide an alternative perspective on subcultures, settings and organisations. By overly frowning upon the apparent ethical transgressions of covert research, we can stifle and censor the sociological imagination rather than enhance it. My call is for a rehabilitation of covert research.
\end{abstract}

\title{
Keywords
}

covert, deception, emotion, ethics, ethnography, risk, violence

\section{Introduction: a covert ethnographic gaze}

In this article, I shall draw on my nomadic ethnographic research on bouncers in the nighttime economy to explore a covert stance in fieldwork. In particular, I aim to reflect on the retrospective and longitudinal nature of my covert immersion in the field and the challenges of dealing with such data. A common fear factor here is the problem of 'old data' that is typically assumed to be outdated, distorted and invalid, which I partly hope to debunk. This is not about crude recycling of data but a more nuanced type of reshaping,

\footnotetext{
Corresponding author:

David Calvey, Manchester Metropiltan University, GM409, Geoffrey Manton Building, Rosamond Street West, Manchester, Greater Manchester, MI 5 6LL, UK.

Email: d.calvey@mmu.ac.uk
} 
as more data is gathered. After some contextualization of the setting and the subculture of the door order, I shall reflect on some situated 'ethical moments' in the field as well as consider the key issues of passing, manipulated self, embodiment, emotionality and risk. Finally, I shall consider the position and value of covert research more generally.

My interest in covert research has developed from a wider interest in creative and innovative ethnography over a lengthy period of time, which I see covert research as being firmly part of. Part of my reasoning here is that covert research is a way to immerse oneself in and try to analyse deviant subcultures and stigmatized occupations from the inside in a rich, intimate and thickly descriptive manner. Covert ethnography is part of a reflective sociological imagination that can also help shed light on the emotional dimensions of fieldwork as well as contribute, albeit disruptively, to important and shifting debates on self and other, ethicality, embodiment, risk, danger and edgework. One of my aims here is in exploring the particular approach of covert ethnography but not in privileging that approach.

For some covert research is transgressive and violates, offends and trespasses against any democratization between the researcher and the researched. This is a crude, stigmatized and simplistic view of covert research, which trades on a type of research moralism (Hammersley and Traianou, 2011), that needs to be challenged. The finger pointing at covert research in favour of overt research often assumes and appeals to a simplistic and reductionist version of informed consent that, in field reality, can be partial and ambiguous. Covert research needs to come out from the 'methodological closet' and be rehabilitated. Part of the reason for being in the closet is both the marginalized treatment of the approach and the lack of a more dedicated literature on the approach, in comparison to other approaches in qualitative research. Additionally, the evocative image of the cover researcher is tied up with filmic stereotypes, popular investigative journalism and expose media headlines, which tends to sensationalise the area.

Covert research can be a creative and imaginative strategy from which to explore the everyday world. Clearly, it is not always appropriate and has significant ethical considerations and baggage attached to it. Neither am I characterising covert research as some sort of methodological panacea. It is one method among several in the toolkit, alongside innovative visual, virtual and sensory turns. My aim here is to encourage fairer readings of covert research and hopefully more diverse usage from the wider social science community.

\section{Covert passing and retrospective participant observation in a demonized subculture}

The location of Manchester, England for the case study, which is where I both live and work, is highly strategic and saturated in popular culture in the form of Gunchester, Gangchester and Madchester attention grabbing media headlines. This small-scale project was a post-doctoral study undertaken independently and funded by myself when I was a temporary lecturer in the Sociology department at Manchester University. The research was done in the evenings and I was paid in cash for my role as a bouncer, which at the time was part of the informal economy, so it was practically achievable. I had done 
fieldwork previously for my doctorate so it was not an alien venture for me. I had failed to gain formal funding for the project by various research councils but pursued it opportunistically anyway, with the strong support of my former supervisor and mentor, a respected and long serving professor in the department. The fieldwork was prior to the current and much more restrictive ethical regimes of Institutional Review Boards and University Ethical Committees. Such bodies and review processes do play a useful role in regulating and guiding professional research but they can also stifle some covert forms of research, with a disconnect between their ritualized guidance and complex field realities. Rather than shelve the project until I received funding in the future, if at all, I wanted to study an interesting and, at the time, very under investigated area in an innovative and appropriate way.

This article builds on previous publications on the topic but it offers a more dedicated interactionist and ethnomethodologically inspired picture of the everyday world of bouncers and the associated ethical challenges of studying and layering it over time. I deliberately shelved and censored some data and time managed publications due to the fears over personal incrimination. There had been police and media attention on some places and individuals that I had researched, compounded by my first publication in 2000 attracting sensationalist headline attention from the local press. I was still working and living in the area that I had researched, a strategy that some researchers actively avoid. Like Howard Parker (1974) in his famous study of juvenile delinquency with a Liverpool street youth gang, similarly met sensitive publication problems due to witnessing some minor criminality. In some ways, this could have been overly conservative on my part, but this was part of the territory of researching bouncers in the night-time economy of Manchester in a specific era of moral panics (Cohen, 1973).

The project was also not a traditional one with a definite finishing date. My exit from the field and the associated management of my post-fieldwork self was a messy and protracted one. For several years I was recognised around the city by bouncers when out socializing and had to 'go back into character' (Calvey, 2000) to manage the situation. I also found myself still making mental notes on the door order during this period, which critically informed future publications. My study has some parallels with Holdaway (1982) in his landmark covert insider account of the British Police. He reflects on the clash of obligations and loyalties of research and performing the actual job he was employed to do as a serving officer. Holdaway usefully argues that covert research is a type of 'masking' but with a heightened, possibly even exaggerated, fear of 'unmasking' many years later. He also encountered sensitive publication issues in terms of time management and content.

Bulmer usefully defines retrospective participant observation as a mode concerned with 'experience recollected in academia' (1982: 254) and often related to biographical familiarity with the setting. An interesting contemporary example of this methodology is the study of the negotiated interactional strategies and counterfeit intimacy of erotic table dancers by Ronai and Ellis (1989). A key part of this study is the specific use of covert retrospective participant observation as part of a 'layered account' by Ronai, who was an erotic dancer herself some year prior to publication. This inside experiential view attempts to demystify a stigmatized occupation, which has some parallels to bouncers in terms of deviant status and spoiled credibility. 
Another provocative contemporary example is Pearson's covert work on football hooliganism. On his doctoral work in 1995, he reflects that: 'large amounts of ethnographic data were put to one side for well over a decade' (2015: vi). What he describes as 'shelved data', which fed into his later key publications, such as his cogent 2009 journal article 'The researcher as hooligan: where "participant" observation means breaking the law', which echoes some of the immersion paradox of my own role as a bouncer. He reflects on the ethical justification of his 'personal ethnographic journey' (Pearson, 2015: iii):

In the days before institutional research ethics committees were commonplace, I was able to adopt the method of covert participant observation with little opposition. I chose this method primarily to avoid distorting the field so that I could gather more accurate or 'natural' data, but also because I was fearful for my personal safety should I admit to being an academic researcher' (Pearson, 2015: v).

Like Pearson and football hooliganism, bouncers were strongly associated with violence, gangsterism and illegality, particularly in terms of collusion with recreational drug supply. Adopting a covert approach to the topic, would allow for easier access to such a subculture. Such retrospection has clear problems and limitations in terms of memory distortion, sentimental reconstruction and selective nostalgia but it should not be crudely discounted as a methodological resource, that in reality, many ethnographers, not just covert ones, routinely trade on.

In terms of the fieldwork setting, I was 'badged up', to use the argot, by completing my Door Safe short course in December 1995, which was jointly run by Manchester City Council and Greater Manchester Police. After this, I spent six months from January to June in 1996 doing a range of different doors in Manchester city centre covertly. This was a purist type of covert research in that it did not have any gatekeeping, follow up interviews or retrospective debriefing arrangements of any kind, as many covert studies have. In terms of fieldwork observations, I recorded some conversations with a hidden micro audio tape-recorder and routinely made field notes after a work shift had finished at home. If discovered, I would have come clean as an independent researcher not commissioned by a University, funding body or agency or indeed an undercover police officer or gonzo journalist. Transcribed data and fieldwork notes was securely stored and I used pseudonyms throughout. I was very anxious to protect and safeguard the anonymity of those involved and the venues studied, particularly as they had not make an informed choice about their involvement in the research. I had set some moral boundaries about witnessing and reporting criminality and I was as ethically responsible and reflective as I could be in the setting. Clearly, you cannot plan for all emergent ethical contingencies in the field, particularly with such a covert approach, but I had psychologically prepared myself as best I could and genuinely wanted to minimize any danger, risk and harm to both myself and the participants.

As well as working on ten different doors, pubs and clubs, in my brief door career, I also actively hung around other doors, in covert bouncer mode throughout the six-month period of my nomadic ethnography. This socializing with other door staff that I was not working with was both a productive complementary way of observing and eavesdropping on the wider door community as well as being a way of networking for more work. 
Six months later at the end of the fieldwork, after covertly passing at various venues, I had been accepted by the bouncers of the most famous night-club in Manchester as being 'in the firm' and offered further work. This is when I chose to formally finish the study, although my exit from the field became much more protracted and lengthy than I had initially assumed.

Everyday clichés and stereotypes classify what 'everybody knows about' bouncers and in turn demonizes, vilifies and maligns them (Calvey, 2000; Monaghan, 2006; Hobbs et al., 2003). Thus, the topic has a sort of intriguing 'armchair value'. If these men were typically 'the lads' of the counter school culture (Willis, 1977) then they have grown up and are now doing doors. In terms of gender, I predominantly worked with male door staff, although there are now more females doing door work with related research on the gendered door (Hobbs et al., 2007; O’ Brien, 2010). My sociological curiosity was to expose and explore this area and to a certain extent demystify and debunk it. The reality that I encountered was that bouncers were a complex and diverse heterogeneous group of individuals with a range of dispositions, personalities and motivations to do door work. Some individuals traded on and used certain masculinity labels to accomplish the work but many ran counter to the 'folk devil' stereotype (Cohen, 1973).

I had reflected at length on the choice of and justification for doing covert research prior to entering the field. I also suffered guilt syndromes and agonised over whether to use a key informant continually throughout the fieldwork period. Doing covert research does not remove ethicality from the researcher but it radically mediates the management of their situated ethics. This involves types of ongoing ethical self-regulation and moral boundary work as displayed in the ethical moments later in the article. Doing a covert study was a decision that was not taken lightly or flippantly, due to the potentially detrimental consequences for both the researcher and the researched. My intention here is not to present covert research as in any way a heroic, cavalier or belligerent business.

In terms of body capital and image, I had trained in martial arts for several years and made contact with a local door agency by openly asking local doormen on several pubs and clubs for 'any work' in Manchester city centre. They were never informed of my research role at any point during the research. My 'hardness passport' of martial arts substantially helped entrée. Put simply, with a stocky seventeen stone build, I looked and sounded the part and quickly became part of the monopoly of muscle (Hobbs et al., 2003) that made the industry work. My fabricated bouncer self was deliberately and wilfully manipulated as was Patrick (1973) in his famous study of a Scottish juvenile gang. As I gained more experience, my short door career of six months became more credible as I nomadically moved around different doors. I had engineered my physical and cultural self in specific and symbolic ways to credibly pass in the setting.

My cultural capital in terms of social class background had significant parallels with the bouncers. What I have previously described as 'Getting on the door and staying there' (Calvey, 2000). Due to my biographical familiarity with the setting, having previously clubbed in the city for several years, the topic was part and parcel of my cultural backyard. In this sense, my covert passing and access was far less extreme than other organizational settings, which often require sensitive and time consuming gate keeping. In a sense, the research was very opportunistic. 
My covert role was profoundly dramaturgical (Goffman, 1959, 1963, 1969, 1983) throughout and employed deliberate and sustained misrepresentations of self. Part of my covert passing was the complex mimicry of their interaction rituals, including demeanour, etiquette, dress, argot, postures, persona and gestures. I wore a standard black bomber jacket and was called 'pony tail Dave'. I would feign interest, sympathy and humour when necessary to fit in. Put simply, my covert goal was to be treated as one of the 'ordinary lads' on the door. Thus, I wanted to get close to them without them getting close to me.

One of the particular methodological challenges in this type of covert fieldwork was managing the tension between instigation tactics and naturally occurring data throughout the fieldwork period. The reality of covert fieldwork can involve instigation tactics and moves. For example, as well as eavesdropping on conversations, I would regularly ask bouncers to repeat certain door stories, with the excuse of a feigned hearing problem and would attempt to get more time during the night 'fronting the door' as I searched for 'where the action was' (Goffman, 1969). I also visited the toilet quite frequently to check on my concealed micro tape-recorder. Most of the bouncers were convinced that I had significant hearing and bladder problems.

The analytic move here was to investigate the everyday world of bouncers in a faithful manner (Bittner, 1973) with thick descriptive adequacy (Geertz, 1973) that attempts to capture some of their routine practices and mundane reasoning (Pollner, 1979). It is an attempt to explore bouncing through the 'lived experience' (Geertz, 1973) of 'doing' the doors. It was a way of working out both if and how forms of hyper-masculinity played out 'in the doing'. Covert research could provide a different way of unpacking the subculture of bouncers. My sensibility was not to ironize, correct or romanticise the bouncers and in so doing present them as cultural dopes and fodder for stereotypical sociological tropes about violence and brutalization.

\section{The door order and the bouncer self}

The burgeoning nature of leisure capitalism presents interesting issues around the regulation of violence and hedonism in the commodified night-time economy (Hobbs et al., 2003). The night-time economy has witnessed an increasing regulatory architecture centred on various moral panics about the new cultures of binge intoxication (Measham and Brain, 2005) and mob disorder (Hayward and Hobbs, 2007). My initial research phase was prior to the establishment of the Security Industry Authority (SIA), the organization responsible for regulating the private security industry in the UK, which was established in 2003. My later research phases extended beyond this date. Doors have been increasingly professionalised and decriminalised over the years, but there are still links to the past.

Door work is a collaborative and collective accomplishment. There is an ecology of door labour wherein tasks and roles are co-ordinated in and through a team. Fronting the door was more high status than internal patrols, although both were needed. As a door person you knew the door code and geared towards it in an implicit way. Membership of the community equals some understanding of the trade and requires no lengthy explanations of it (Rubenstein, 1973). Camaraderie was an essential ingredient of the bouncer 
world. The strength of the collective bonds on the door was a form of fictive kinship (Woodward and Jenkings, 2011), that enabled the door order to be both achieved and sustained. There could be internal rivalry, disputes and clashes between the door team, particularly over the supervisory role of head doorperson. To ignore this would paint an overly romantic picture of door work.

Similar to Colosi (2010), in her semi-covert ethnography of lap dancers in the UK, the strength of camaraderie and the specific 'codes of conduct' amongst the dancers parallels ideas of the bouncer code and membership of the door community. Colosi was motivated to challenge the myth that portrays lap dancers as 'victim or villain, lost in a dark, shameful and dangerous world' (2010: 6). 'Having a laugh', to coin a common phrase, on the door was also an essential component of galvanizing group identity as well as being a standard coping mechanism. Colosi cogently comments that humour helped: 'to shape lap-dancing as a form of anti-work' (2010: 182). Sanders similarly captures the highly routinized character of door work in dealing with boredom: 'While these guardians of club land might be seen as glamorous by punters, the job was marked by its routine banality, sparingly interrupted by unpleasantness' (2005: 243).

The bouncer subculture had a pronounced occupational door code, that was routinely displayed in a 'telling and showing' manner (Wieder, 1974). There was no written rulebook but a set of relevancies and schemas, both practical and symbolic, that I had to gear into. To a certain extent, the setting was self-explicating (Pollner, 1979,) but I still had to learn the ropes quickly. The door staff stuck together in a survival type mentality. What Thompson (2001), a former experienced bouncer, elegantly refers to as 'watch my back', in his popular memoirs of bouncing. This is part of a well-established lay and practitioner literature on the area. Although, bouncers represented the pub or club management and worked with greeters, the door was their territory, their remit of control, their domain. A classic 'them and us' reasoning pervaded this subculture. The solidarity of the door team was primary and honorific, with the overwhelming logic of door work being one of deterrence. Bouncers did play an active part in customer selection (Thornton, 1995), although much of this was prior customer self-selection in terms of the type of club and particular night it was.

Door work was also profoundly about trust. The routine work tasks and troubles (Zimmerman, 1969) were deeply embedded in such teamwork based trust relationships. The door code is oriented to in a taken for granted manner by competent members in that setting. Primarily, the exercise of authority on the door by bouncers providing or refusing entry to the venue. The bouncer's sense of self is intimately tied up with such a legitimation of authority. The management set the code for admittance with the bouncers applying it. Door work also had status, a type of street kudos, displayed in the way that certain customers and friends could be treated in a privileged way, such as not queuing or paying. A sedimented and tacit corpus of routine and mundane methods, procedures, rules and competencies are then built up as part of the everyday work of bouncers. In many senses, it was specific stocks of knowledge (Schutz, 1973) that were tacitly displayed in the doing of the work. In many ways, it was also a type of lay psychology in terms of reading customer actions and intentions.

The authority of the door staff is sanctioned by their employment by the licensee to keep order by 'reasonable force', if necessary. Most of the bouncers I encountered used 
force as a last resort and used other persuasion and diffusion strategies to maintain control. This involves boundary work as to what can be legally and morally sanctioned in the control of aggressive clientele. It also a game of damage limitation in that the cardinal rule was getting the conflict outside of the premises both as swiftly and safely as possible. It then becomes the remit of the police as regards public disorder, although there typically was blurring around this as doormen often acted as good citizens in nearby disputes and conflicts between customers. The door order is classically then a negotiated one (Strauss et al., 1963) between bouncers, customers and management.

My fieldwork self was then partly an embodiment and performance of certain types of masculinity and physical culture (Monaghan and Atkinson, 2014), some of it being in hyper forms, which was both individually and collectively performed. Clearly, masculinity is a complex field in itself, which is not the sole topic of this article. What I would broadly characterise as a form of 'choreographed bravado' and 'respect management', which were central parts of the symbolic, physical and psychological deterrents used to run doors. Both the fear of violence as well as the actuality of it also plays an important part in such situated performances. One can easily paint a disproportionate picture of commodified violence in the night-time economy, as some commentaries have, which feeds into the mythical picture of bouncers.

A vital issue is not to reify violence in the everyday world of bouncers and in so doing exaggerate its significance but to enquire into how bouncers routinely gear into and cope with it as part of their mundane reasoning. Most of the violence I witnessed was between intoxicated customers with bouncers intervening to stop conflict escalating and being effectively arbitrators in arguments. Importantly, violence thus becomes an ambient feature of their work environment and in turn part of their occupational 'war stories' rather than a more saturated one, which feeds the one-dimensional view of bouncers that some commentaries have successfully traded on. For me, bouncing, along with other frontline occupations, is clearly a form of emotional labour (Hochschild, 1983), which requires interactional fronts and masks to accomplish the work.

Hobbs et al. (2002) list a 'gambit of skills' including local knowledge, verbal negotiation skills, bodily capital and fighting ability as part of the 'door trade' and 'door lore'. Despite being a fragmented and rather nomadic occupation (Sanders, 2005) there was a strong sense of community amongst bouncers. Fincham (2008), in his study of the blurring between the work and leisure distinctions of bicycle messengers, usefully refers to this as 'subcultural affiliation'.

It is widely acknowledged that bouncers are doing a type of private policing and are the primary agents of social control in the night-time economy (Hobbs et al., 2003; Winlow, 2001; Winlow et al., 2001; Monaghan, 2006). Rigakos (2002), in his study of Canadian bouncers, characterised as the 'new para-police', although bouncers typically distanced themselves from the police in many respects. Bouncing was centrally about, drawing on the seminal work of E.C. Hughes, doing the 'dirty work' $(1962,1971)$ of the night-time economy. Hence, dealing with aggression, intoxication and hedonism are all a mundane part of such work. Hughes classically wrote of the need to study: 'arrangements and devices by which men make their work tolerable, or even glorious to themselves and others' (1971: 342). Although attempts have been made to professionalize bouncing, as the occupation tries to distance itself from historic associations with 
criminality, private security still involves types of esteem, stigma and taint management (Hansen Lòfstrand et al., 2016). Indeed some bouncers still trade on that older legacy to do the work.

Part of this private policing is also in dealing with the drug economies in the nighttime economy, particularly in popular city centre nightclubs. The question of collusion is a complex and important one. Sanders, in his semi-covert study of the drug economy and drug culture at a large London night-club, argues that it was 'self-contained, self-policed and self-sufficient' (Sanders, 2005: 253) with a small amount of bouncers involved. Similarly, my experience was that recreational drug dealing in some venues that I worked in was tolerated, when operated discretely, and only became significant if violent incidents escalated because of it. Thus, a very small number of bouncers received 'kickbacks' or monetary payments from drug dealers to allow entry and turn a 'blind eye'. Customers were routinely searched on entry but not to an interrogation police standard, although some VIPs were typically not searched. Most of the nigh-clubs and pubs were rhetorically seen to operate a 'no drugs policy' but a very strictly enforced policy would have been 'swimming against the recreational tide'. Silverstone, who investigated the rave culture in a London night club semi covertly, sensibly states on this: 'In terms of policing these spaces, violence was a rarity, as a working drug market did not want the police attention that might come with routine violence' (2006: 148).

\section{Managing situated 'ethical moments' on the door: guilt syndromes, deviant knowledge and emotional dilemmas}

The question of ethical parameters plagued my mind throughout the fieldwork in a convoluted series of 'what if scenarios'. Throughout the fieldwork, I was concerned with the tension between what I was occupationally expected to do as a bouncer and my personal moral compass and ethical boundaries. These following vignettes are some scenarios which display 'ethically important moments' (Guillemin and Gillam, 2004). Ethical dilemmas then vitally become a situated 'doing' that are managed and satisficed, but not resolved, in the setting (Calvey, 2008).

\section{Being recognised}

When a former female University student recognised me on the door at the beginning of the fieldwork period, I had to assertively deny all knowledge of her as my cover could have been blown. Because of her insistence of knowing me and my view that she was intoxicated, she was then refused entry to the premises and barred for a short period of time from it. It was a rare one off occurrence, effectively my fieldwork nightmare, that I had sustained guilt syndromes about.

\section{Witnessing violence}

I also became a witness to violence on several occasions. I did not intervene when a door was breached by a local gang and a doorman was assaulted inside the club in front of me. I was warned it was 'personal' and accordingly stood back. Another incident was when 
I witnessed a bouncer being seriously assaulted by a rival door team by being thrown into a canal. Customers called the police but I was told clearly by him to say 'nothing' as he did not want to be seen as 'a grass', or police informant, and did not press any charges. Thankfully, he suffered superficial damage and no police action followed. I was fully aware that dealing with violence or, in most cases, the fear of violence, was part of the occupational territory. It is very important here not to overplay violence in the work world of bouncers as this could easily slip into producing an exaggerated and disproportionate account of their world.

\section{Mistaken identity}

I suffered from mistaken identity when, entering a nightclub off duty for research purposes, I was stopped at the door by a well-known and very intimidating doorperson from an infamous Manchester criminal family, who was eventually murdered. My heart stopped as I thought he had discovered my true research purposes and was going to get some personal retribution for this deception. I was mistaken for somebody else that they wanted to have 'serious words with'. Once let in paranoia had got the better of me. I never spent long in the venue that evening and could not fully concentrate on any observational matters that evening. I was emotionally shaken by the incident and abruptly reminded of the risks of doing this covert project.

\section{Being confided in}

A very different type of ethical moment, in what I loosely describe as 'turning the tape recorder off syndrome', was when a young door man opened up to me about his brutalization and the potential effects on his new born baby son. I was drinking alone with him at a nightclub, at his invitation, and when I got the next round in, I quickly turned the tape recorder off in the toilet. For me, this was a solution in the moment and not a general abandonment of realism as I was still taking mental notes and it is the basis of current reflection. His identity has always been anonymized in any writings. He was confiding in me about his personal life and trusting in me to 'say nowt' to the other doormen. He didn't want his son to end up getting 'a shit job like he had'. He was exposing his vulnerability to me, some of which was his criminal past, yet it was based utterly on deception as he thought I was one of them and not a researcher.

Clearly this is not a definitive taxonomy of my field experiences but some key scenarios from which to ethically unpack and reflect further on. There is not a methodological right or wrong answer here but it is more a display of my particular covert condition. They display the situated complexity and contingent temporality of ethical decision-making. Similar to Pearson (2009), in his covert study of football hooliganism, I was walking a legal tightrope in doing such a study, in terms of witnessing, recording and tolerating some aspects of illegality. An example of this, was when I witnessed the doormen taking cash from customers for very late entry to a popular nightclub and then dividing this up, without the knowledge or consent of management. I declined part of the cut but made no comment on it, which was my way of working out a comfortable ethical solution at the time. Hence, my ethnography was one at the edge (Ferrell and Hamm, 1998). Moral 
judgments (Johnson, 1985) are then complex, liminal and contingent matters that you practically work out in the doing and not fixed states in ethnographic research.

This article is not a treatise on covert ethical decision-making. These 'ethically important moments' placed me in ambivalent positions, sometimes surrounding illicit activity and guilty knowledge (Polsky, 1967). Managing situated ethics was akin to what Westmarland, in her innovative overt study of policing, elegantly calls 'encounters with ambiguity' (2001: 531) as she tried not to be an 'ethnographic referee' on the values and world-views of the group under study. Namely, sustaining a type of bracketing and noncorrectional stance in ethnography, which is challenging. Doing covert work is thus not devoid of any ethical integrity and has simply gone native and taken a side, as a crude stance on covert research would assume, but rather displays different and subtle forms of ethical self-regulation and situated negotiations and manoeuvres.

\section{Emotionality, embodiment and risk-taking in a covert ethnography that never quite finished}

This nomadic covert ethnography was of a sensual and embodied kind. It was the voluntary and deliberate experience of risk-taking and edgework (Lyng, 2005). At times, I felt I was at the limits of my deception and doubted how long I could sustain this role for. This was not a morally 'anything goes' situation. I was aware of my own personal ethical parameters throughout the fieldwork period. Within the ethnography, risk becomes intimately part of the phenomenological experience. The 'buzz' of doing doors was an intoxicating but fatiguing mixture of pleasure, thrill and adrenalin alongside stress, fear, anxiety and apprehension. Despite being based on fakery, ironically, I made some temporary but genuine bonds and friendships with the doormen throughout my fieldwork period. Simultaneously, it was also a continual source of betrayal and guilt.

I am partly inspired by Wacquant's (2005) reflexive ethnography of boxing, which shifted from covert to overt over his three year fieldwork period. His embodied approach has clear parallels to bouncing with his drive to inhabit their craft and habitus. Body image and bodily capital are the keys to a more intimate and nuanced understanding of their trade and habitus. For Wacquant, boxing, which is demonized and vilified by some, is a visceral pursuit and in order to understand it the researcher had to immerse themselves into the 'sensuous pizzazz' (Wacquant, 2005: 464). For Monaghan, in doing his fieldwork on bouncers: 'the multidimensional body becomes a topic of, and resource in, ethnographic fieldwork' (2006: 238), which had some similarity to my own ethnographic logic.

Despite various job offers, I left by not turning up for my shift, binning my mobile phone and avoiding the venues where I had worked at. Nothing grand but rather a quiet 'disappearing act' was my fieldwork exit strategy, although it took much longer to fully extract myself. My covert research role in this nomadic 'sub-aqua ethnography' (Calvey, 2000) was demanding in a performative sense. The idea of the post-fieldwork self was a very significant one for me. After I had left the field there was some local sensationalist press coverage of my research work, which exaggerated my knowledge of criminality amongst the door community. This compounded the sensitive management of the postfieldwork self and the time management of publications. 
My ethnography then became a longitudinal one, by drift rather than design, which had the distinct advantage of reflecting on my bouncer self in different stages of the research process. So on several occasions, long after I had left the field, when I was recognised by door staff I felt that I had to sustain my door identity and 'go back into character'. In such situations, I made jokes about early retirement, low wages and personality clashes with management as reasonable ways to explain my exit. Some just assumed I was still working on the doors and thus on some occasions, I would purposively let them think that if it was more expedient in the situation. Sometimes, this resulted in privileged free entry to the club, as I did not want to offend them. Whilst inside the club I felt like, and partly acted as if, I was still on duty as a doorman. Hence, the post-fieldwork self was a deeply ambivalent one. It was like being stuck in a research project with no closing date, but it also offered an opportunity to gather more and different data over an extended period of time.

Clearly issues of data distortion and reconstruction involving memory slippage, glamorization and romanticization must be sensibly borne in mind here but many ethnographers trade on such data, frequently unacknowledged, and it should not be excluded from our analytic resources and reasoning. Our immersion in fields are often messy experiences, which are not neatly organised, packaged and phased.

\section{Conclusions: a covert rehabilitation of sorts}

I hope that I have resisted becoming another form of 'zoo keeping studies' (Gouldner, 1968) but produced a reflexive account that views emotion as both a resource and topic in field research (Holmes, 2010) and not a horror to be hidden away, glossed over or sanitized out. Doing bouncing, and in so doing managing my 'secret self', was an actual lived field experience for me, with my fellow bouncers unwittingly being collaborators. This has been a sort of confessional account, which is retrospective and longitudinal, on the covert condition and relational ethics, which is hopefully not another narcissistic or exotica narrative. I encourage others to provide more 'warts and all' fieldwork accounts, importantly both overt and covert. Also, as I was rejected from formal funding, it is partly a call for greater research resilience.

The seminal work of and the critical scholarship around Cressey, Dalton, Festinger et al., Goffman, Humphreys, Milgram and Rosenhan, to name a famous few of the traditional tropes or 'usual suspects' (Calvey, 2017) in covert research, have historically shaped the discipline in various ways. However, an over focus on these exemplars can be limiting as there is a submerged, yet rich and instructive, covert diaspora available. I do not conceive of the covert field as a consolidated, integrated and incremental one but rather a diverse, dispersed and fragmented one in the social sciences.

There is a more dedicated literature on covert research (Bulmer, 1982; Calvey, 2000, 2008, 2013, 2017; Denzin, 1968; Erikson, 1967; Herrera, 1999; Homan, 1980; Miller, 1995; Mitchell, 1993; Roulet et al., 2017; Spicker, 2011). On closer inspection, many covert studies are not purist forms of deception, with many employing overt gate keeping and key informants, which bellies against the stereotypical cavalier and heroic picture of the covert researcher as using covert methods belligerently and exclusively at all costs. The reactions to covert research have been unnecessarily hyper and alarmist, with the elements of risk and danger often being inflated. 
This article is not taking an extreme 'anything goes' stance, which removes the valuable role of ethical review. Clearly vulnerable groups and legal boundaries must be sensibly managed, but are we missing a trick. This call is to recognise and appreciate the role of covert research in field research, when appropriate, rather than deny its potential and scope in the social sciences. What Miller has elegantly described as: 'reconsidering the least used method' (1995: 97). Roulet et al. more recently stress that: 'the study of deviant behaviours, secretive organizations and socially important topics is often only possible through substantially covert participant observation' (2017: 487).

Covert research is clearly not to everyone's analytic taste but the commitment is to explore different and creative ways of constructing ethnographic narratives. The covert ethnographic role can be a deeply artful one that offers a way to form intimate insider accounts about a wide range of topics. It should become a more standard part of the ethnographic craft (Atkinson, 2015) rather than be outcast as a methodological pariah. In certain forms of autoethnography, online lurking within cyber ethnography and bystander observations of public behaviours, there seems to be a growing appetite for covert research, although it is certainly not becoming mainstream. There remains a classic fear and fascination about covert research.

\section{Funding}

This research received no specific grant from any funding agency in the public, commercial, or not-for-profit sectors.

\section{References}

Atkinson P (2015) For Ethnography. London: Sage.

Bittner E (1973) Objectivity and realism in sociology. In: G Psathas (ed.) Phenomenological Sociology. New York: Wiley, 109-125.

Bulmer M (1982) When is disguise justified? Alternatives to covert participation observation. Qualitative Sociology 5(4): 251-264.

Calvey D (2000) Getting on the door and staying there: a covert participant observational study of bouncers. In G Lee-Treweek and S Linkgole (eds) Danger in the Field: Risk and Ethics in Social Research. London: Routledge, 43-60.

Calvey D (2008) The art and politics of covert research: doing 'situated ethics' in the field. Sociology 42(5): 905-918.

Calvey D (2013) Covert ethnography in criminology: a submerged yet creative tradition. Current Issues in Criminal Justice 25(1): 541-550.

Calvey D (2017) Covert Research: The Art, Politics and Ethics of Undercover Fieldwork. London: Sage.

Cohen S (1973) Folk Devils and Moral Panics: The Creation of the Mods and Rockers. London: Paladin.

Colosi R (2010) Dirty Dancing? An Ethnography of Lap-Dancing. Abingdon: Willan Publishing.

Denzin NK (1968) On the ethics of disguised observation. Social Problems 15(4): 502-504.

Erikson KT (1967) A comment on disguised observation in sociology. Social Problems 14(4): 366-373.

Ferrell J and Hamm M (1998) True confessions: crime, deviance, and field research. In: J Ferrell and MS Hamm (eds) Ethnography at the Edge: Crime, Deviance, and Field Research. Boston: Northeastern University Press, 2-20. 
Fincham B (2008) Balance is everything: bicycle messengers, work and leisure. Sociology 42(4): 618-634.

Geertz C (1973) The Interpretation of Cultures. Selected Essays. New York: Basic Books.

Goffman E (1959) The Presentation of Self in Everyday Life, New York: Doubleday Anchor Books.

Goffman E (1963) Stigma: Notes on the Management of Spoiled Identity, London: Penguin.

Goffman E (1969) Where the Action Is: Three essays. London: Penguin.

Goffman E (1983) The interaction order. American Sociological Association 48(1): 1-17.

Gouldner A (1968) The sociologist as partisan: sociology and the welfare state. American Sociologist 3(May): 103-116.

Guilleman M and Gillam L (2004) Ethics, reflexivity and 'ethically important moments in research'. Qualitative Inquiry 10(2): 261-280.

Hammersley M and Traianou A (2011) Moralism and research ethics: a Machiavellian perspective. International Journal of Social Research Methodology 14(5): 379-390.

Hansen Lòfstrand C, Loftus B and Loader I (2016) Doing 'dirty work': stigma and esteem in the private security industry. European Journal of Criminology 13(3): 297-314.

Hayward K and Hobbs D (2007) Beyond the binge in 'booze' Britain: market-led liminalization and the spectacle of binge drinking. The British Journal of Sociology 58(3): 437-456.

Herrera CD (1999) Two arguments for 'covert methods' in social research. British Journal of Sociology 50(2): 331-343.

Hobbs D, Hadfield P, Lister S and Winlow S (2002) Door lore: the art and economics of intimidation. British Journal of Criminology 42(2): 352-70.

Hobbs D, Hadfield P, Lister S and Winlow S (2003) Bouncers: Violence and Governance in the Night-Time Economy. Oxford: Oxford University Press.

Hobbs D, O'Brien K and Westmarland L (2007) Connecting the gendered door: women, violence and door work. British Journal of Sociology 58(1): 21-38.

Hochschild AR (1983) The Managed Heart: Commercialization of human feeling. Berkeley: University of California Press.

Holdaway S (1982) An inside job: a case study of covert research on the police. In: M Bulmer (ed.) Social Research Ethics: An Examination of the Merits of Covert Participant Observation. London: Macmillan Press Limited, 59-79.

Holmes M (2010) The emotionalization of reflexivity. Sociology 44(1): 139-154.

Homan R (1980) The ethics of covert methods. The British Journal of Sociology 33(1): 46-59.

Hughes EC (1962) Good people and dirty work. Social Problems 10(1): 3-11.

Hughes EC (1971) Work and self. In: EC Hughes, The Sociological Eye: Selected Papers. Chicago: Aldine-Atherton, 338-347.

Johnson M (1985) Imagination in moral judgment. Philosophy and Phenomenological Research 46(2): 265-280.

Lyng S (ed.) (2005) Edgework: The Sociology of Risk taking. New York, CA: Sage.

Measham F and Brain K (2005) Binge drinking, British alcohol policy and the new culture of intoxication. Crime, Media, Culture 1(3): 262-283.

Miller M (1995) Covert participant observation: reconsidering the least used method. Journal of Contemporary Criminal Justice 11(2): 97-105.

Mitchell RG (1993) Secrecy and Fieldwork. London: Sage.

Monaghan L (2006) Fieldwork and the body: reflections on an embodied ethnography. In: D Hobbs and R Wright (eds) The Sage Handbook of Fieldwork. London: Sage, 225-241.

Monaghan L and Atkinson M (2014) Challenging Myths of Masculinity: Understanding physical cultures. London: Routledge.

O’ Brien K (2010) Inside door work: gendering the security gaze. In: R Ryan-Flood and G Rosalind (eds) Secrecy and Silence in the Research Process: Feminist Reflections. London: Routledge, $117-132$. 
Parker H (1974) View from the Boys: A Sociology of Down-Town Adolescents. Newton Abbot: David \& Charles Holdings Limited.

Patrick J (1973) A Glasgow Gang Observed. London: Eyre Methuen.

Pearson G (2009) The researcher as hooligan: where 'participant' observation means breaking the law. International Journal of Social Research Methodology 12(3): 243-255.

Pearson G (2015) Ethnography and the study of football fan cultures. In: A Schwell, N Szogs, M Kowalska and M Buchowski (eds) New Ethnographies of Football in Europe: People, Passions, Politics. London: Palgrave MacMillan, vii-xx.

Pollner M (1979) Self-explicating settings: making and managing meaning in traffic court. In: G Psathas (ed.) Everyday Language: Studies in Ethnomethodology. New York: Irvington Press, 227-255.

Polsky N (1967) Hustlers, Beats, and Others. Chicago: Aldine.

Rigakos G (2002) The New Parapolice: Risk Markets and Commodified Social Control. Buffalo, Canada: University of Toronto Press.

Ronai CR and Ellis C (1989) Turn-ons for money: interactional strategies of the table dancer. Journal of Contemporary Ethnography 18(3): 271-298.

Roulet TJ, Gill MJ, Stenger S and Gill DJ (2017) Reconsidering the value of covert research: the role of ambiguous consent in participant observation. Organizational Research Methods 20(3): 487-517.

Rubinstein J (1973) City Police. New York: Farrar, Strauss and Giroux.

Sanders B (2005) In the club: ecstasy use and supply in a London nightclub. Sociology 39(2): 241-258.

Schutz A (1973) The structure of the life world (volume one). Illinois: Northwestern University Press.

Silverstone D (2006) Pub space, rave space, urban space - three different night-time economies. In: B Sanders (ed.) Drugs, Clubs and Young People. Hampshire: Ashgate. 141-153.

Spicker P (2011) Ethical covert research. Sociology 45(1): 118-133.

Strauss AL, Schatzman L, Ehrlich D, Bucher R and Sabshin M (1963) The hospital and its negotiated order. In: EF Eliot (ed.) The Hospital in Modern Society. London: Collier MacMillan, $147-169$.

Thompson G (2001) Watch My Back. A Bouncer's Story. Chichester: Summersdale.

Thornton S (1995) Club Cultures: Music, Media and Subcultural Capital. Cambridge: Polity Press.

Wacquant L (2005) Carnal connections on embodiment, apprenticeship, and membership. Qualitative Sociology 28(4): 441-471.

Westmarland L (2001) Blowing the whistle on police violence: gender, ethnography and ethics. British Journal of Criminology 41(3): 523-535.

Wieder DL (1974) Language and Social Reality: The Case of Telling the Convict Code, The Hague, Mouton.

Willis P (1977) Learning to Labour: How Working Class Kids Get Working Class Jobs. London: Saxon House.

Winlow S (2001) Badfellas: Crime, Tradition and New Masculinities. Oxford: Berg.

Winlow S, Hobbs D, Lister S and Hadfield P (2001) Get ready to duck: bouncers and the realities of ethnographic research on violent groups. British Journal of Criminology 41(3): $536-548$.

Woodward R and Jenkings KN (2011) Military identities in the situated accounts of British military personnel. Sociology 45(2): 252-268.

Zimmerman DH (1969) Task and troubles: the practical bases of work activities in a public assistance organization'. In DA Hansen (ed.) Explorations in Sociology and Counselling. Boston: Houghton Miffin, 264-284. 


\section{Author biography}

David Calvey is a Senior Lecturer in Sociology at the Manchester Metropolitan University (MMU). Prior to working at MMU he held teaching and research positions at the University of Manchester, Liverpool John Moores University, The Open University, and was a Visiting Fellow at the University of Queensland. His publications and research interests span ethnography, covert research, humour studies, martial arts, ethnomethodology, organizational creativity, private security, and the night-time economy. He is a member of the British Sociological Association and a Fellow of the Higher Education Academy. His recent book is Covert Research: The Art, Politics and Ethics of Undercover Fieldwork (Sage, 2017). 